\title{
The archaeology of conflict-damaged sites: Hosn Niha in the Biqa' Valley, Lebanon
}

\author{
Paul Newson ${ }^{1} \&$ Ruth Young ${ }^{2}$
}

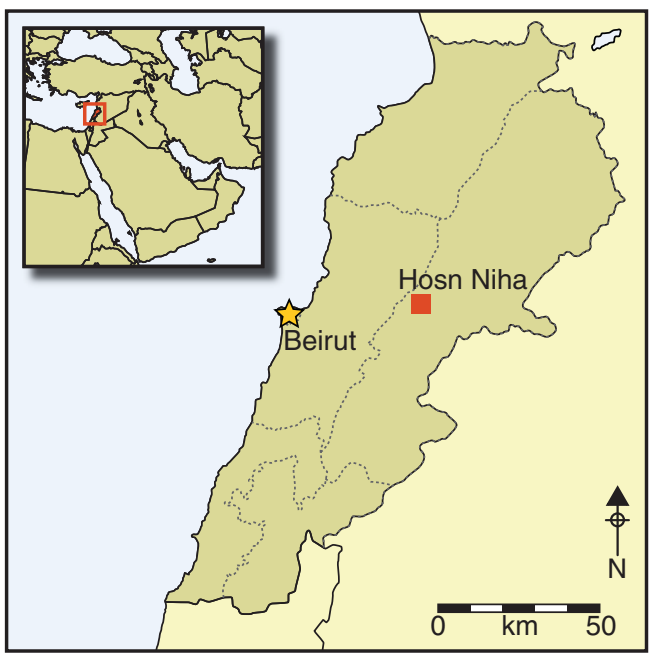

Archaeological and cultural heritage is always at risk of damage and destruction in areas of conflict. Despite legislation to protect sites and minimise the impact of war or civil unrest, much archaeological data is still being lost, not least in the Middle East. Careful research design and methodological recording strategies tailored to sites destroyed by conflict or looting can, however, provide much more information than previously imagined. This is illustrated by a case study focusing on the Roman settlement and temples at Hosn Niha in the Biqa' Valley, which were severely damaged in the 1980s during the Lebanese Civil War. Sufficient information was recovered to reconstruct many details, including the chronology and development of the site.

Keywords: Lebanon, Roman settlement, conflict archaeology, looting, Cultural Resource Management, GIS

\section{Introduction}

When faced with the destruction of archaeological sites through conflict and the accompanying loss of knowledge, what can archaeologists do? In this paper, we use the example of a site in Lebanon, which has been severely damaged by multiple conflict episodes, to show that a great deal can be learned from an apparently destroyed site by careful fieldwork and analysis. Conflict is arguably an integral part of human interaction, and archaeological studies have provided evidence for conflict from as early as the Palaeolithic (Thorpe 2003). Conflicts have occurred throughout prehistory and history, and they are an inescapable evil in many parts of the world today (Boylan 2002). The human cost in any conflict is high and, obviously, protecting people has to be the first priority during such periods. However,

1 Department of History and Archaeology, American University of Beirut, Bliss Street, P.O. Box 11-0236, Beirut, Lebanon (Email:pn04@aub.edu.lb)

2 School of Archaeology and Ancient History, University of Leicester, University Road, Leicester, LE1 7RH, UK (Email:rly3@le.ac.uk) 
archaeologists, politicians and many others recognise that damage to heritage is irreversible and has very serious, lasting consequences. Boylan (2002: 44) notes the longevity of the practice of destroying, defacing or converting significant religious and national buildings and monuments in times of conflict. The impact of war on archaeological sites is rightly an area of great significance and concern to archaeologists and other heritage professionals, and it is increasingly becoming an area of research and debate, both within and outside academic circles.

The reality is that cultural heritage has been destroyed and continues to be destroyed by conflict. Preventing or avoiding conflict itself (world peace) is the ideal, and, failing that, minimising damage to cultural property through education and awareness is a critical aim being addressed by many (Ali et al. 2013; Stone 2013). Hamilakis (2009) has critically evaluated the issues raised when archaeologists work with invading military forces and their governments; his key recommendations include solidarity and collaboration with archaeologists within affected countries, and complete transparency whenever archaeologists are obliged to engage with military powers. We agree with these recommendations (indeed, we have both practised the former in various countries), but until the aims of universal peace and heritage education are even partially achieved, archaeologists in many parts of the world are faced with archaeological sites that have been heavily damaged, where there is an apparent concomitant loss of unique information. The aim of this paper is therefore rooted firmly in pragmatism; given the global impact of conflict on heritage and the lack of any long-term solutions to this situation, we argue that it is important to find ways of dealing with the many archaeological sites that have been so damaged. We do not suggest this as an alternative to prevention and long-term solutions but purely as a way of working with the resources that we do have, and we present the case study of Hosn Niha, a Roman-Byzantine village located in the Biqa' Valley of Lebanon, as an example of obtaining maximum information from a site badly damaged by conflict.

\section{Lebanon: war damage to cultural property and heritage}

Lebanon is a signatory to the Hague Convention for the Protection of Cultural Property (1954) and the Hague Protocol for the Protection of Cultural Property (1954), but not the Second Protocol (1999) (ICRC n.d.). On the other hand, local laws have been passed in recent times to safeguard cultural property, such as N37, Law of Cultural Property 2008 (Savage \& Rempel n.d.; UNESCO n.d.). Having this overarching legal framework in place is obviously good, but, historically, events have rendered its practice inoperable and so it has made no difference to the damage caused to the country's irreplaceable cultural heritage. The key event-the Lebanese Civil War-lasted from 1975-1990, with various different actions occurring within this time period, such as the Israeli invasion of Lebanon in 19821983. Some 40000 Syrian troops entered Lebanon in October 1976 as part of an Arab Deterrent Force agreed at an Arab League Summit. These Syrian troops occupied Lebanon until 2005, when the assassination of Rafik Hariri (then former Prime Minister) resulted in the Cedar Revolution (demonstrations calling for an end to Syrian influence on Lebanese politics) and the subsequent withdrawal of the Syrian military presence. A further period of fighting occurred in 2006 and is known by various names such as the July War, the 2006

(C) Antiquity Publications Ltd, 2015 
Lebanon War and the Hezbollah-Israel War (Hirst 2010). Various localised outbreaks of fighting have occurred in different parts of Lebanon since 2006, along with an increasing number of fatal bombings and other violence, which is largely linked to the ongoing war in neighbouring Syria.

Lebanon is very important archaeologically, located as it is at the intersection of the cultural spheres of the Mediterranean and the Fertile Crescent. Sites from a wide range of periods and civilisations have been identified and explored here, not least the wellknown World Heritage Sites of Byblos, Tyre and Baalbek, and the two lesser-known World Heritage Sites of Anjar and the Qadisha Valley with the Forest of Cedars (UNESCO n.d.). The importance of Lebanon as an archaeological resource has ensured that it has received extensive media coverage of the damage sustained to its cultural and archaeological sites over many years. Robert Fisk (1993) has on occasion reported the widespread looting and destruction of archaeological sites in Lebanon, a practice sanctioned in the chaos of 15 years of civil war. Fisk (1993: 243) also noted the thousands of tons of artefacts stolen and shipped out of the country, and the thefts from both the American University of Beirut Museum and the National Museum (both in Beirut). Sites and archaeological stores in other parts of the country, such as Byblos and Tyre, were also badly affected (summarised in Savage \& Rempel n.d.). Tombs and sarcophagi were particularly targeted for gold items and other treasure found in burials (Fisk 1993: 244-48).

Contrasting reports of damage during the July 2006 war highlight some of the issues raised by Hamilakis (2009) with regard to the dangers of having only a very narrow, colonialist view of what constitutes 'culture'. A report by National Geographic News is enthusiastic about the way in which major sites such as Baalbek and Tyre "appear to have emerged unscathed" (Milstein 2006). This contrasts sharply with Tahan's (2006: 107) account of ICOM (the International Council of Museums) findings, where it was observed that "[i]n July and August 2006, the war in Lebanon caused tragic human losses, as well as massive damage to its infrastructure, environment, and heritage", and that "villages with traditional homes have been swept away. These are not only part of a tangible heritage, but also an intangible one of artisans passing down traditions of artefact production from one generation to the next" (Tahan 2006: 107). ICOM (cited in Tahan 2006: 107) also said that "Byblos, Baalbek, and Tyre, all three UNESCO World Heritage Sites, have been affected by the war".

Although sites such as Baalbek tend to dominate news reports about war and cultural heritage in Lebanon, there are, of course, many more sites not of World Heritage status but which are regionally important. For example, Kamid el-Loz, a multi-period tell located in the Biqa', and a substantial provincial settlement of the interior, is a type of site far less studied than the major port cities such as Tyre (Ward 1994: 72-73). Syrians and Israelis fought in the Kamid el-Loz region in 1982 and their front lines, in the form of huge earthen embankments, not only ran across the valley floor but also the site itself. The site was then bulldozed extensively by local and national treasure hunters in the 1980s (Seeden 1989: 3; Fisk 1993: 250-51). However, excavations resumed in the 2000s, directed by Professor Marlia Heinz, and they have resulted in the recovery of a great deal of new archaeological information, which is being published in ongoing reports (latest summary: Heinz et al. 2010). This work has shown that even when destruction appears severe over a large area, targeted excavations can be highly effective. 


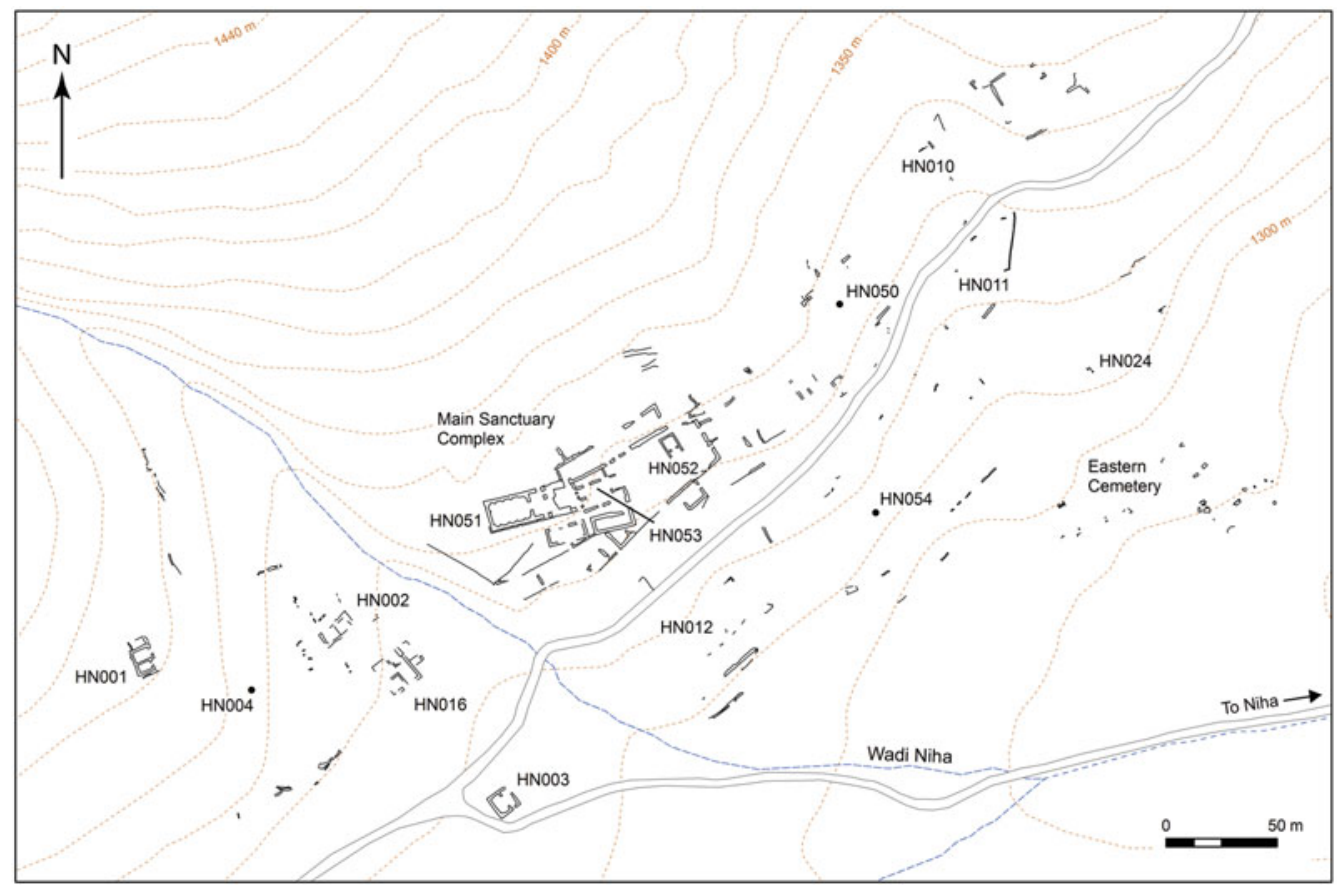

Figure 1. Key features at the site of Hosn Niha and its walls, as mapped by differential GPS.

\section{Hosn Niha: the site and project aims}

Although a large-scale site survey of the Biqa' Valley was undertaken in the 1970s (Marfoe 1978, 1995, 1998), relatively little is known about the development of the settlement in the region beyond the key site at Baalbek. This is particularly the case for the Graeco-Roman period, which saw great change in the valley as a considerable area was given over to colonists from outside the region. A few small-scale surveys and inscription collections have gathered data from this period, but this has been insufficient to answer specific key questions. One of these core questions, which relates to the development of off-tell settlement, is concerned with the appearance of stone temples at particular sites in the foothills of the mountains that frame the Biqa' Valley; and, since impressive standing remains of many of these temples survive, they have received much more attention than other sites (Krencker \& Zschietzschmann 1938; Nordiguian 2005; Aliquot 2009). In contrast, we know very little about the local populations who paid for and built such temples. Neither do we have information about their wider cultural practices or indeed about their daily lives away from the temples.

The narrow Niha Valley is located in the foothills of the fault zone on the south-western side of the main Biqa' Valley and runs perpendicular to it. The site of Hosn Niha is situated in the upper regions of the Niha Valley at the head of a small but relatively wide fertile vale of $c$. 100ha of useful agricultural land (Figure 1). Set on the lower slopes of the scarp, facing the vale, are the prominent remains of a monumental, stone-built, Roman-period (C) Antiquity Publications Ltd, 2015 


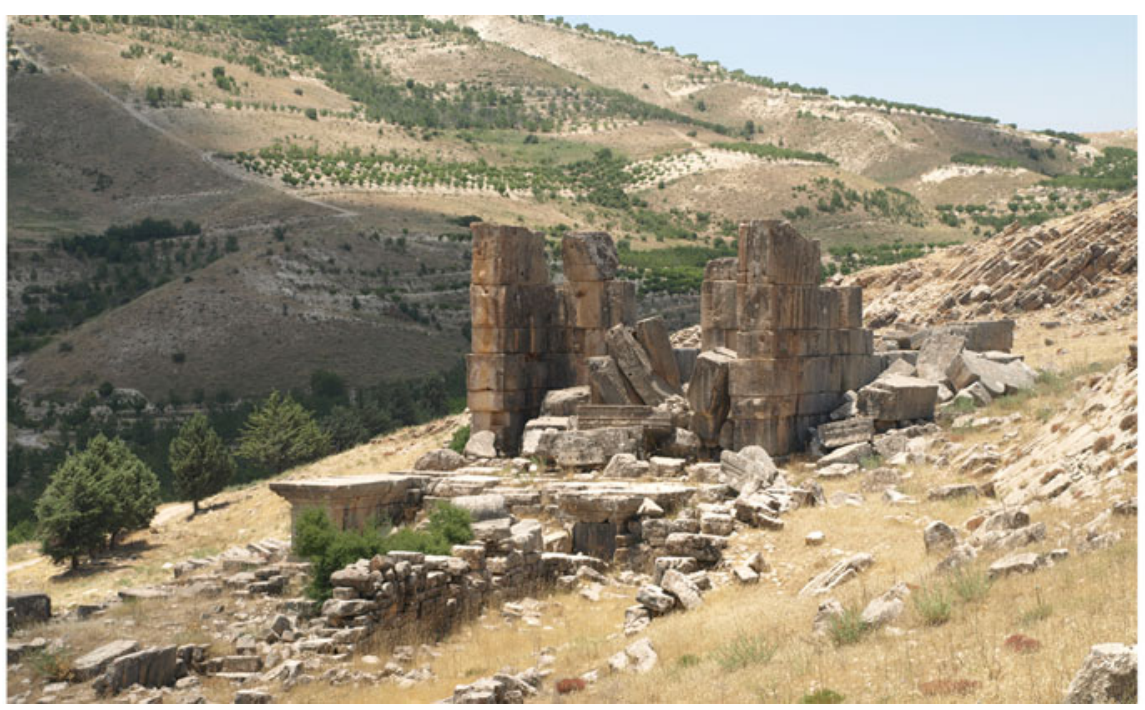

Figure 2. The remains of the second century AD monumental temple at Hosn Niha; looking south-west.

temple complex of the second century AD (Figure 2). Below this complex, yet inextricably associated with it, is the site of a village, much of which displays signs of heavy disturbance caused by military activity, opportune digging and agricultural encroachment. Due to the monumentality, dramatic setting and well-preserved nature of the temple, the site of Hosn Niha has been a destination for European travellers and scholars interested in its history and architecture since the early nineteenth century (e.g. Burckhardt 1822: 29-30; Warren 1870: 204-206). Interestingly, these early visitors barely comment on the site beyond the monumental temple. The earliest investigations of the temple-sanctuary complex were by Krencker and Zschietzschmann in the early 1900s (published in 1938); more recently, a detailed reassessment was completed by Jean Yasmine (2005, 2006, 2009). Krencker and Zschietzschmann (1938: 122) also took the time to record a further isolated religious site (HN001) to the south-west of the main temple-sanctuary, but they otherwise paid no attention to any other structures, with their only comment on the village structures being that "these provide a picture of complete ransacking, there is hardly a stone present which would provide a clue to an interpretation of the debris".

Working after the turn of the millennium, Yasmine did carry out a cursory study of the settlement site alongside his temple-sanctuary study, noting that it had been the target of clandestine diggers for some time. He recorded that the looting situation had worsened considerably during the Lebanese Civil War and particularly during the final phases of the conflict period at the end of the 1980s, when "treasure hunters equipped with bulldozers came to excavate the village: the traces of their actions [were] noticeable on the site. Unfortunately, this action disturbed irreversibly a good amount of evidence" (Yasmine 2006: 14). Undoubtedly, the systematic bulldozing was a result of the opportunities provided to various figures who at different times exerted local control during the civil war period and so can be directly related to the conflict. Smaller scale looting events were not necessarily 


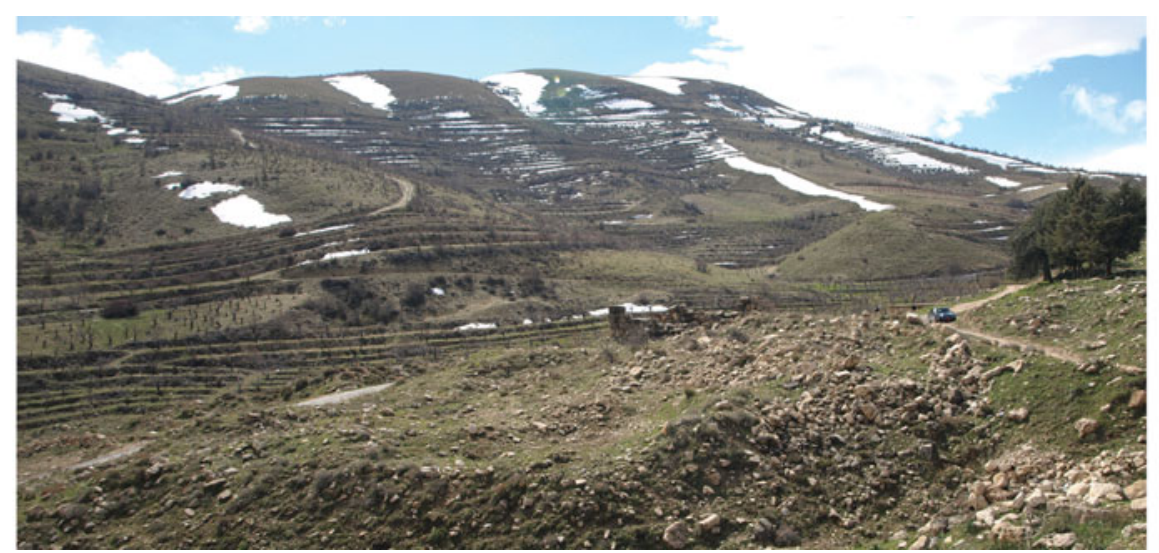

Figure 3. The area south of the temple sanctuary, between HNOO3 and the Wadi Niha; this was once the core area of the village but is now bulldozed piles of rubble; looking south-west.

the direct result of conflict, although activities at the site during that period will have raised awareness of the site, and of the artefacts recovered, at a regional level. However, the disturbances had brought pottery sherds to the surface and allowed Yasmine to identify some of the residences established on the lower slopes (Yasmine 2006: 14, 47-48). From studies of this pottery, he suggested that the settlement occupation extended from its initial foundation as part of the Roman colony of Berytus in the first century $\mathrm{AD}$ until its abandonment at some unspecified time during the seventh century AD (Yasmine 2006: 57-58, 233).

During preliminary visits to the site, it was clear to us that large areas of the settlement below the main temple sanctuary had suffered substantial damage, if not outright destruction (Figures $3 \& 4$ ). Indeed, the impression gained from other scholars was that very little valuable information could now be obtained from the site outside of the two monumental temples (Aliquot 2009: 303) and, in a recent work on the temples of Lebanon, it was stated that "the criminals have also extended their misdeeds to the village area that extends to the south and on the side of the mountain to the west of the sanctuary where mechanical means were employed to bulldoze the stratigraphy across the entire site" (Nordiguian 2005: 65). The perceived state of damage to the site raised serious questions about whether attempting to study the destroyed village remains would be possible at all and whether useable information would even be recovered. In other words, should the condition, presented by extensively war-damaged and looted sites, such as Hosn Niha, force archaeologists to ignore them and conclude that important potential research questions cannot be addressed? We would argue the opposite- that with the correct research design, critical questions can be addressed; that with the appropriate field and analytical techniques, very useful data can be collected from badly damaged sites; and that a great deal can be learned from unpromising beginnings.

In deciding to investigate the site, the current project had a number of specific aims to address concurrently. The first of these was to place the development of the main sanctuary in context and reconnect the development of such temples, commonly found within the Biqa' region, to the villages located near them. Further, it is clear that beyond the templesanctuary at Baalbek and excavations of the Graeco-Roman levels at Kamid el-Loz, very (C) Antiquity Publications Ltd, 2015 


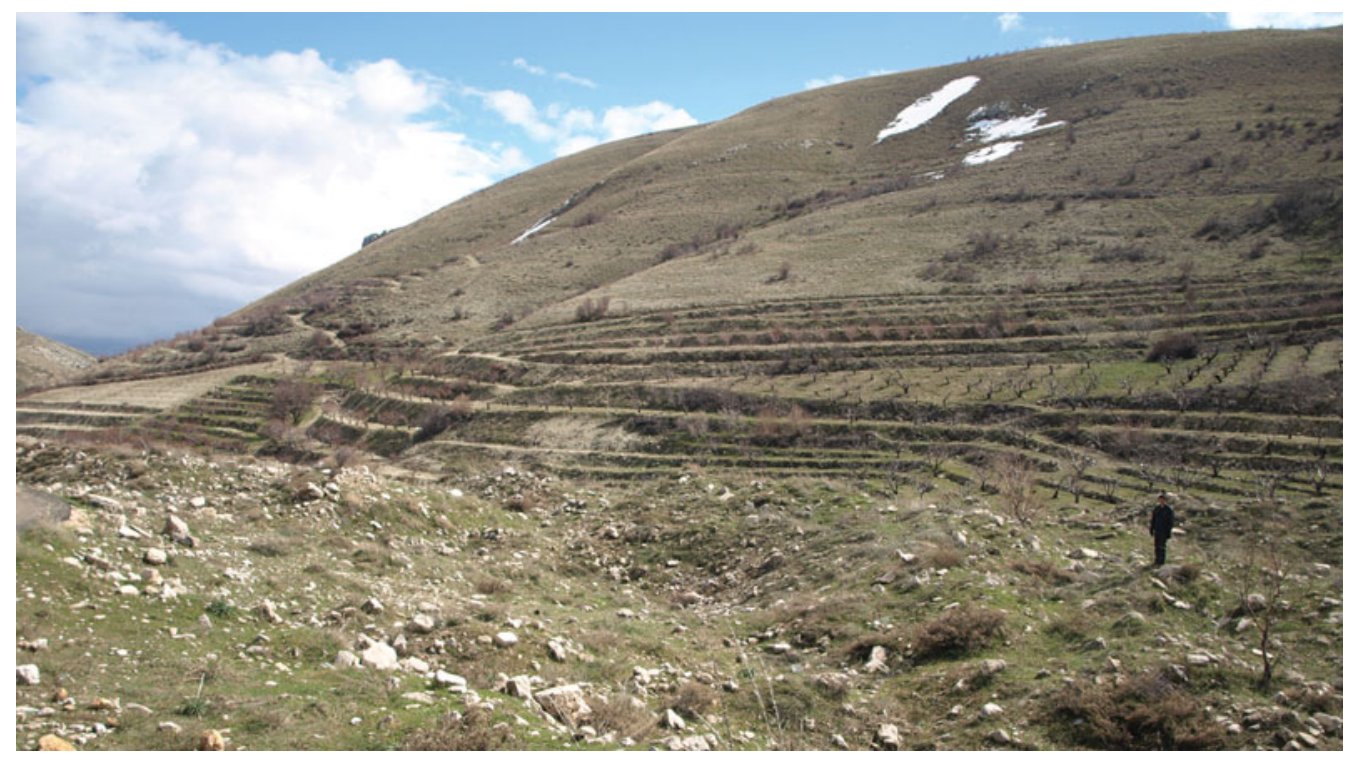

Figure 4. The area to the immediate south-west of HNOO3 (beyond the track seen on the left edge), which was bulldozed during the period of the Lebanese Civil War; looking south-east.

little analysis has been attempted in relation to the development of rural Graeco-Roman settlement sites of the Roman colony within the Biqa' Valley. Therefore, the second aim of the fieldwork was to obtain a more nuanced understanding of the foundation, development and structure of the Roman colony of Berytus. A third explicit aim was to make a detailed assessment of the extent of the damage to the site itself and to quantify the nature and effect of other processes on the site, such as encroaching agricultural development.

\section{Fieldwork strategies}

The use of appropriate methodologies is critical to obtain useful information from such a damaged site. These methodologies must be tailored to the research aims and questions but also sufficiently robust to allow the recognition and recording of data from sites or areas of sites that have been heavily bulldozed or looted. The main issue we faced was how best to record the highly disturbed and damaged surface remains in a way that was quick and systematic, and that would allow data to be collected for effective analysis to begin to address the main project aims. This consideration led to the use of methodologies based on surface survey and pottery counting and collection in order to determine whether it was indeed possible to learn about the nature and morphology of the settlement, and to attempt to delineate different patterns of use across the site. The construction of a data-rich Geographic Information System (GIS) environment, in which initial research analyses could be generated, future research areas identified and potential Culture Resource Management needs formulated, has been integral to the methodological approach (Newson \& Young 2014). 
As well as using methods that could effectively help us to achieve the main research goals, it was also necessary to map and categorise the extent of destruction simultaneously and explicitly, despite the extensive site damage. This mapping allowed us to factor in any bias the destruction could have produced in our interpretations of the evidence. Furthermore, it would greatly assist in determining areas of future research, in addition to allowing us (and the Lebanese Department of Antiquities) to monitor any potential

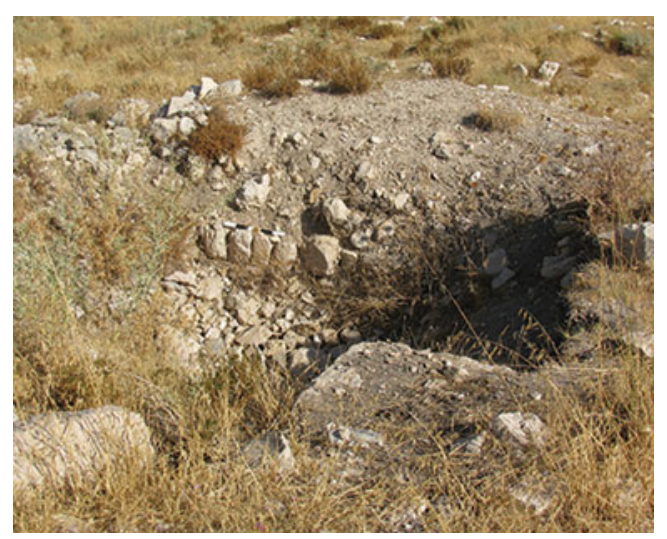

Figure 5. An area of small-scale illegal excavation at location HN012, which has exposed structural walls. site damage. From ground observations made on preliminary site visits and during the fieldwork, examination of available aerial photographs from 1959, satellite imagery and accessible photographs of the site, we were able to establish four basic types of damage: bulldozing, clandestine excavations, older agricultural land expansion (pre-2005) and recent agricultural land expansion (post-2005). Evidence for each of these was plainly distinguishable: bulldozed areas were characterised by deep trenches surrounded by steep-sided banks of rubble, up to $3 \mathrm{~m}$ in height, interspersed with large levelled banks

(Figures 3 \& 4); clandestine excavations by pits with spoil heaps (Figure 5); agricultural land was ploughed and planted with vine and tree crops, or recently cleared (Figure 6). It seemed from these observations that while large areas had been heavily bulldozed, the displaced material had not been moved very far, certainly less than $50 \mathrm{~m}$ in extent. During fieldwork, the spatial extent of these four types was mapped using plans and supplemented by Global Positioning System (GPS) measurements of specific features and then fed into the site GIS.

When gathering data to address the central project aims during two short seasons in 2011 and 2012, two main approaches were used. The first involved recording any visible features using a differential GPS that allowed for the very accurate spatial positioning of surface features, while also providing a simple but accurate representation of them. The features recorded included tombs, the alignments of stones that constituted various wall types, and building structures (Figure 7). Moreover, as a supplement to this work, certain structures of potential importance were planned in more detail through a combination of GPS and by hand. While surveying the different wall structures, it was noted that there were a significant number of carved worked stones scattered across the site. These worked stones included column shafts, bases and capitals, door lintels and jambs, cistern or well-covers and sarcophagi. Each worked stone was photographed and its location coordinates were recorded on a handheld GPS. The second approach centred on the intensive recording of surface pottery. To record the density of surface pottery and obtain a sample of diagnostic sherds across the site, a series of transects were organised, along which team members walked and either collected diagnostic sherds or used clicker counters to register the numbers of sherds on the surface within a $1 \mathrm{~m}$-wide corridor. Obtaining indications of the density (C) Antiquity Publications Ltd, 2015 


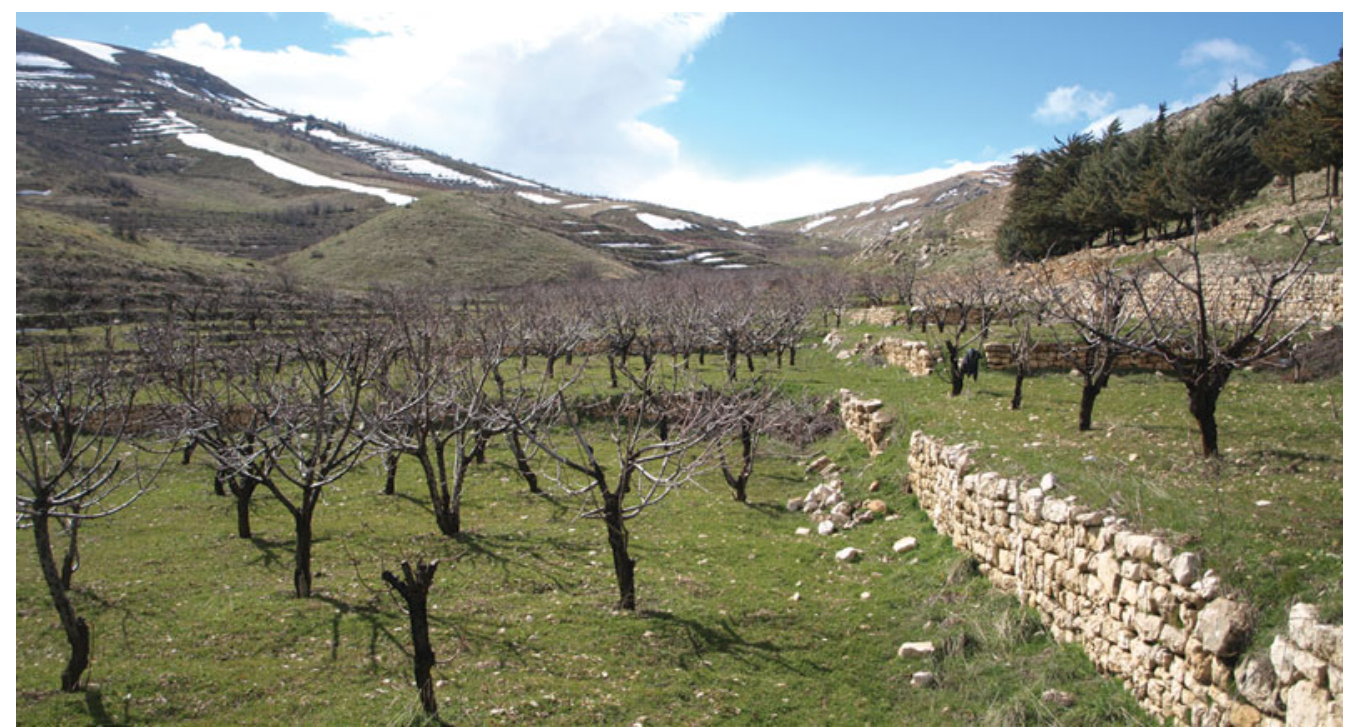

Figure 6. The area at the south-western edge of the site, landscaped and planted with fruit trees: the modern terrace walls have been constructed from remains of the Graeco-Roman settlement. Photograph taken looking west.

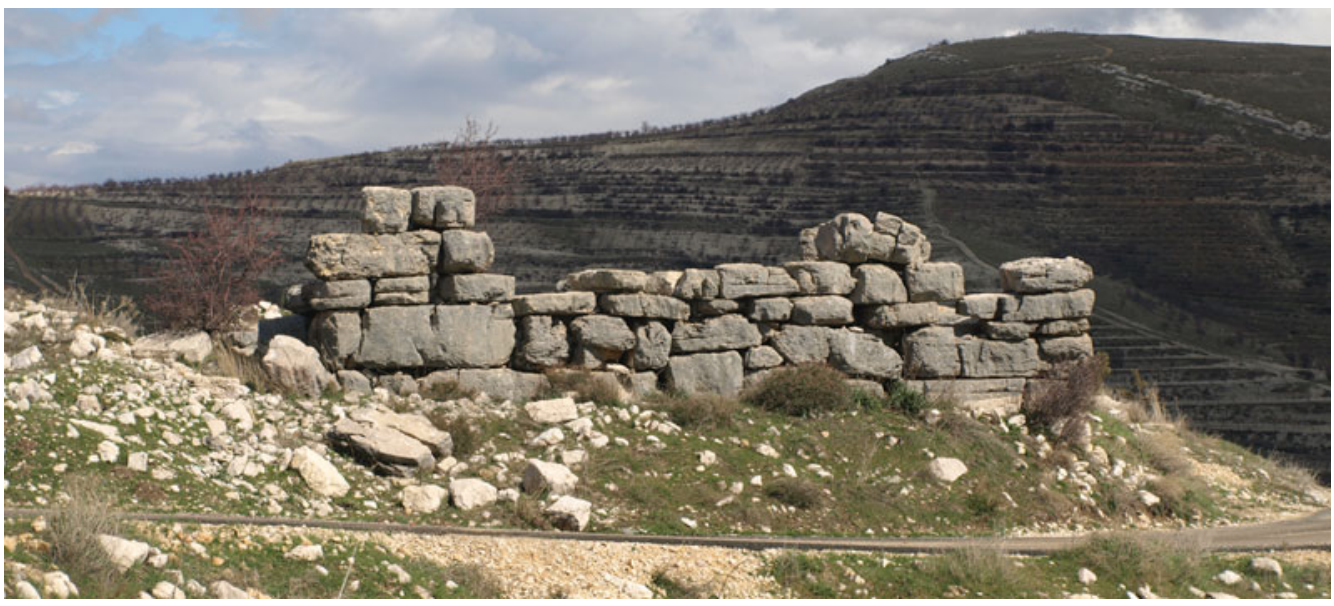

Figure 7. HN003: a substantial stone structure still standing in the core occupation area of the site; looking towards the north-east.

of the surface pottery was designed to help define the spatial limits of the settlement. The collection of diagnostics had two purposes: to obtain a representative sample of the variety of pottery from the site; and to provide a sample of pottery from which preliminary indicators of date and function could be assigned to the settlement site, and even provide some pointers to different activity zones within the settlement. As the data were collected they were immediately entered into the project GIS (Figure 8).

(C) Antiquity Publications Ltd, 2015 


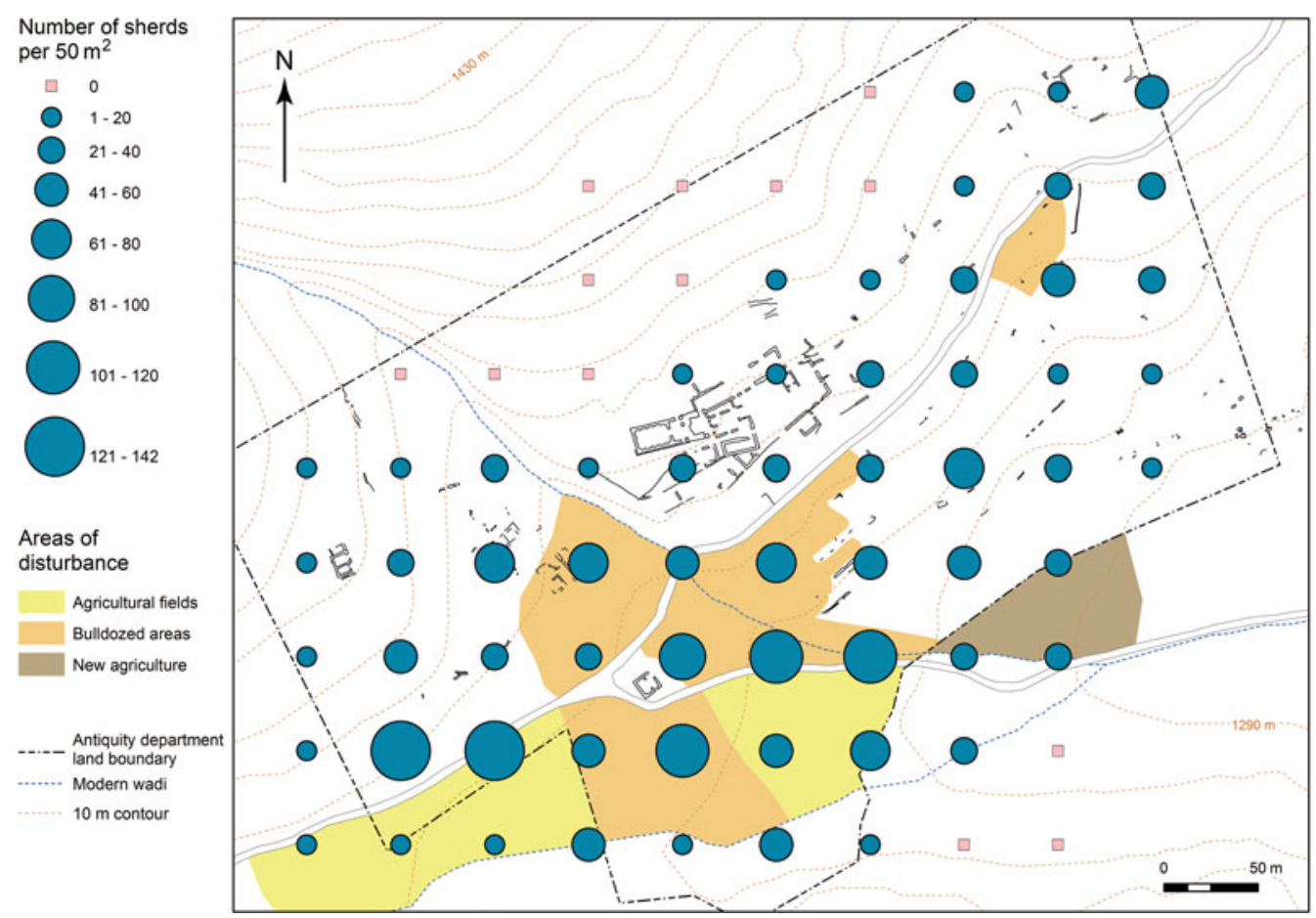

Figure 8. Map showing transect quantities of clicked sherds and mapped areas of damage across the site.

\section{Discussion}

The programme of feature-recording has directly challenged the long-held idea that the village of Hosn Niha had been so badly damaged that either nothing of value remained, or that what does remain is so badly damaged that archaeologists will gain no information from studying the village site (Krencker \& Zschietzschmann 1938; Aliquot 2009). Instead, our systematic recording has revealed a diverse range of well-preserved structure types and other features beyond the main sanctuary (HN051-53). These include a subsidiary, non-GraecoRoman-style cult high-place, building (labelled HN001 on the map of the site), quarries to the immediate north of the main sanctuary, zones of rock-cut tombs in the hillsides and a designated cemetery to the east with a variety of tomb types, from stone sarcophagi to individual cist tombs and communal rock-cut tombs. There are also several structures right across the site that we have interpreted as dwellings. Of these structures, only those that were well preserved with substantial standing remains were planned and explored in detail, such as the cult complex HN003 and the structure HN016, which is probably a Byzantine farmstead (Yasmine 2006: 15). However, our feature-recording methodology has systematically expanded our understanding of what survives, so that it is now clear that a number of dwellings and associated structures are still discernible at other locations around the site. To the south and east of the main cult complex, in situ terrace wall sections were noted, along with numerous short lengths of wall and illegally excavated pits that exposed (C) Antiquity Publications Ltd, 2015 


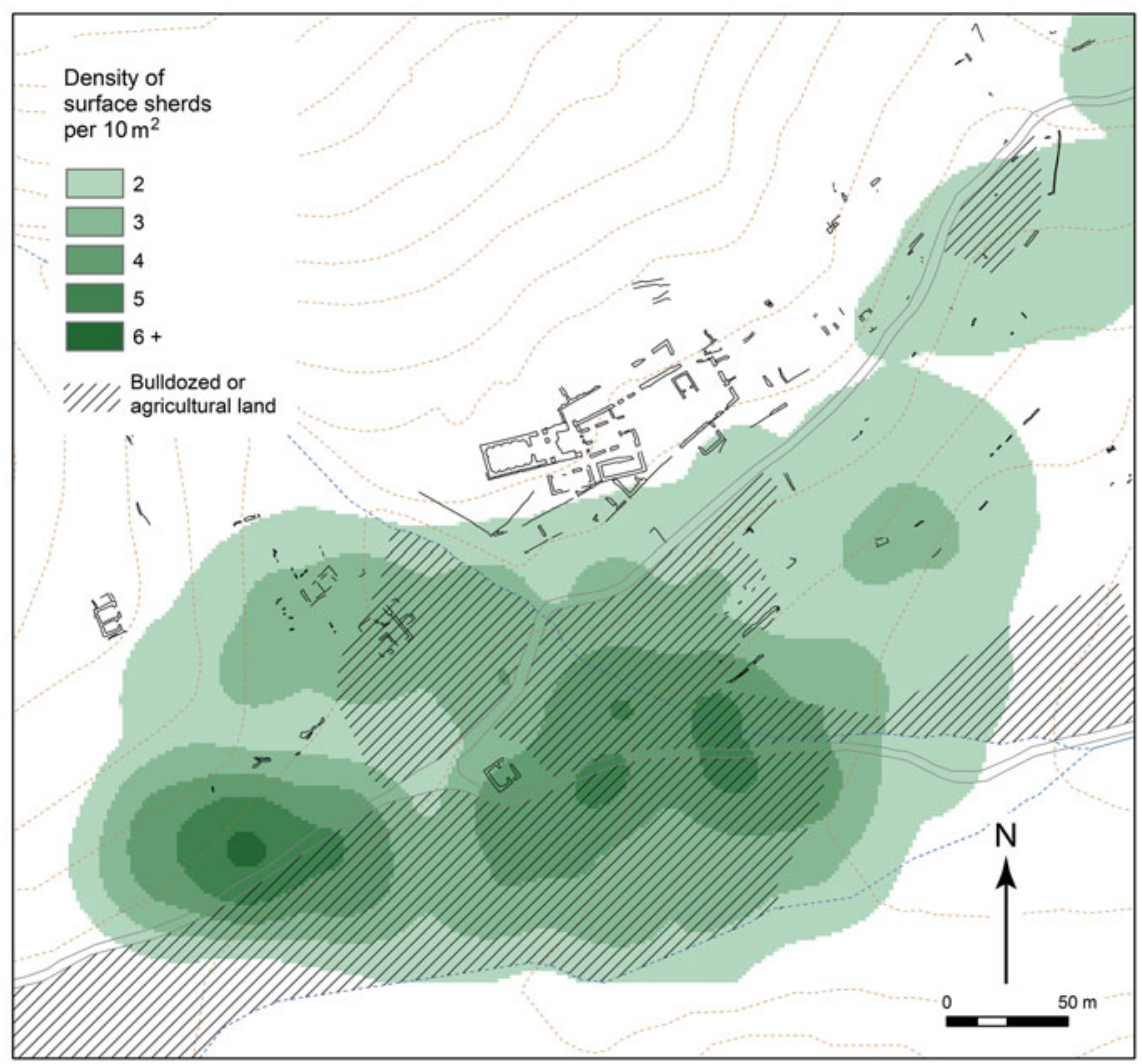

Figure 9. GIS-generated density map of clicked surface sherds from the results of the $50 \mathrm{~m}$ transect series across the site.

wall-enclosed spaces (e.g. HN012; see Figure 5). These in situ exposed walls (of which feature HN012 is a good example) indicate that on this steep slope below the main temple complex, walls are preserved, almost certainly belonging to buildings that lined an upper terrace. Beyond this central area, our results show that settled occupation was focused in the two small side valleys at either end of the site, which have evidence for dispersed dwellings (HN002, HN016, HN010 and HN011; Figure 1). These dwellings were probably discrete farmhouses, set within walled courtyards that took advantage of the flatter ground and more sheltered climate of the valleys.

The results from the intensive fieldwalking exercise revealed concentrations of both clicked surface sherds and diagnostic sherds across the site. From this raw data, density maps have been generated within the GIS and so have provided us with a general idea of the extent of the occupation areas of the settlement (Figure 9). The delineation of the inhabited spaces of the settlement, where the dwellings were situated, was implied by the location mapping of worked-stone features, such as door lintels. This area was further clarified in the recording and classifying of extant walls and the subsequent differentiation between the exposed walls of buildings and associated walls on one hand and terrace walls on the other (Figures $1 \&$ 10). Ongoing analyses of the diagnostic pottery collected are allowing us to develop a more 


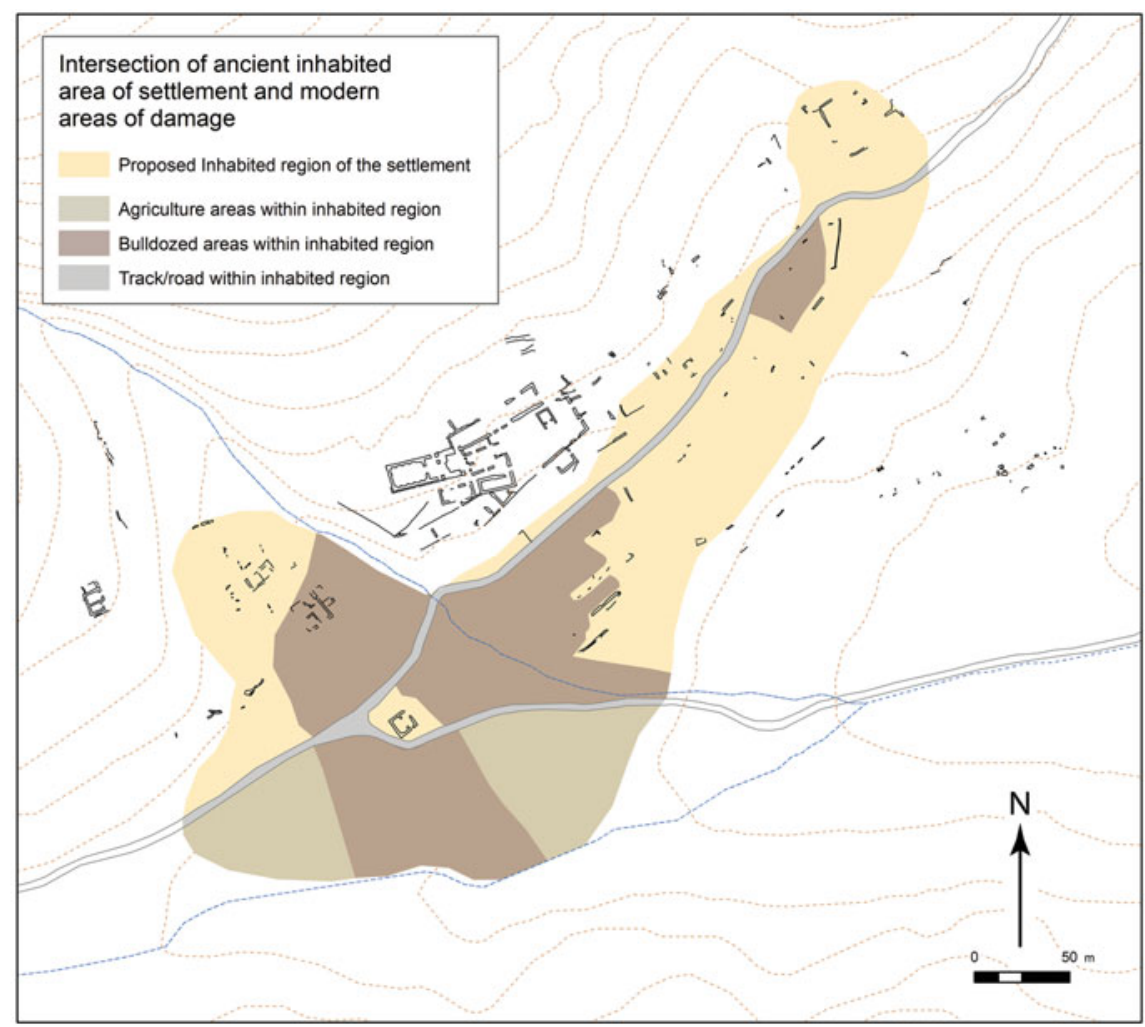

Figure 10. Calculated inhabited zone using density mapping of surface sherds, the recording of structure walls and other evidence such as the location of door lintels.

nuanced understanding of settlement occupation and the morphological development of the village over time. For example, glazed sherds characteristic of the early medieval period were collected in the vicinity of, and within, stone structure HN003, but nowhere else (Figures 1 $\& 7$ ), and a number of interpretations can be suggested from this, both in general terms and of a more specific nature. The glazed sherd distribution points to spatial and chronological differentiation in terms of site development: there was a period of re-occupation of the site in the early medieval period, with HN003 being constructed as a fortified farmstead.

It is noticeable that certain areas have higher densities of surface sherds than others, especially by the course of the Wadi Niha in the south-west. These dense areas of surface pottery coincide for the most part with the greatest areas of bulldozing, and this correlation is to be expected as previously buried sherds have been exposed in the bulldozing process. We would argue that the areas that were attractive to bulldoze would have been the core of the settlement, possibly the original point of settlement foundation, the densest areas of occupation and perhaps the longest occupied parts of the village. Environmental factors support this initial interpretation, as these areas lie at the foot of the mountain slope at the point where the angle of the slope lessens considerably, while also lying on the intersection of communication routes both across and parallel to Mount Sannine, and which are within (C) Antiquity Publications Ltd, 2015 
Table 1. The calculated areas and corresponding percentages of each land type within the inhabited area of the village as defined in Figure 10.

\begin{tabular}{lrr}
\hline Land classification & Area $\left(\mathbf{m}^{2}\right)$ & \% of inhabited area \\
\hline & & \\
Agricultural & 8884 & 14.66733 \\
Bulldozed & 20846 & 34.41638 \\
Roadways & 3034 & 5.00908 \\
Damaged & 32764 & 54.09279 \\
Inhabited area & 60570 & 100.00000 \\
\hline
\end{tabular}

easy access of the main wadi flow. The re-occupation of only this part of the site in the early medieval period, signified by HN003, reinforces the strategic and environmentally optimal nature of this area. The analyses of data collected, and the collection methodologies themselves, allowed us to quantify more accurately the extent of damage to the occupied areas of the settlement and to act as a resource catalogue of what remains and where future work can be focused. For example, using simple spatial analytical tools within the GIS investigations, the extent of damage to the inhabited zone of the village was mapped and the results of this are summarised in Table 1 (see also Figure 10). Although these results will never be completely accurate, given a certain level of built-in fuzziness (a GIS data term) in the input data, they do provide a good measure of the damage proportions involved. So from these results we can establish that even though the core of the village has been irreparably damaged, a significant amount of the site remains in situ and with enough surviving features and structural evidence to warrant further investigation.

\section{Conclusion}

Although the village's structures have been very badly damaged over a number of years of conflict-related destruction and additional agricultural encroachment, the use of carefully selected methodologies closely linked to obtaining information with which we can address the research questions has made it possible to obtain a significant amount of data at Hosn Niha. The integration of all of these data has resulted in a good understanding of the detailed organisation of the village and its associated structures. The first results of the analyses have already begun to provide new insights into the relationship between settlement and temple and also of the settlement's history and morphology. Consequently, we are beginning to reveal fluctuations, both spatially and chronologically, in the occupation of the site. So far, the pottery sherds suggest habitation of the site only in certain periods-a large GraecoRoman settlement and a small, geographically focused early medieval occupation, but more work is necessary on this aspect of the project.

Not only is this the first such field project in the Biqa' area to explore these issues, it is one of only a few projects in the wider region to take on the challenge of investigating a site considered too badly damaged by conflict and/or other post-abandonment activities to warrant systematic archaeological investigation. It is clear that socio-political and economic 
conditions during the period of the Lebanese Civil War encouraged the targeted and systematic destruction of the archaeologically rich site of Hosn Niha. Such acts foreground issues of cultural property protection during conflict periods and highlight the need for specific actions and understandings (Stone \& Farakh Bajjaly 2008: 7; Cunliffe 2012: 8). However, many sites such as Hosn Niha also face threats from human activities that are not necessarily directly linked to conflict situations. Damage to cultural heritage from agricultural expansion and looting, for example, also needs to be understood and addressed in terms of protection where possible. When protection has not been possible, or fully effective, the implementation of appropriate methodologies can permit us to obtain a great deal of information from sites that may appear too badly damaged to be worthy of detailed study.

Moreover, through this multifaceted approach, we have been able to appraise the extent of damage to the site of Hosn Niha and further the original research goals. The results of this approach have given us an initial, relatively detailed assessment of the settlement of Hosn Niha, which will provide a valuable foundation for future research and Cultural Resource Management requirements. Although obviously not ideal in archaeological terms, to be able to gain such a lot of important data from a site that at first appearance (see Figure 4) seems to not be worth investing time and energy studying, is important in a world where (sadly) conflict occurs and affects vast numbers of archaeological and other heritage sites. What is clear is that even sites that have been very badly damaged by conflict, and other human and natural events, have the potential to tell us about human activity in the past.

\section{Acknowledgements}

We are grateful to the Directorate General of Antiquities, Lebanon, especially Dr Assaad Seif and Mr Rafi Gerjian for their valuable help. Thanks are also given to the School of Archaeology and Ancient History, University of Leicester, and in particular to Mr James Harvey and Dr Mark Gillings, and to Professor David Mattingly, who read a draft of this paper. We would further like to thank Professors Rubina Raja and Peter Stone for their critical input. Grateful thanks are equally passed to the American University of Beirut, especially colleagues in the History and Archaeology Department and archaeology students who helped in the survey: Jana Alameh, Georges Bellos, Dorothy Chacra, Patrick Hanna, Hassan El Hajj, Yara Idriss, Crystal El Safadi and Lamia Sassine. The fieldwork was funded through grants generously provided by the University Research Board, American University of Beirut.

\section{References}

Ali, I., I. Shah, A. SAmad, M. Zahir \& R. Young. 2013. Heritage and archaeology in Chitral, Pakistan: exploring some local views and issues. International Journal of Heritage Studies 19: 78-97. http://dx.doi.org/10.1080/13527258.2011.643909

AliquOT, J. 2009. La vie religieuse au Liban sous l'empire romain. (Bibliothèque Archéologique et Historique Tome 189). Beirut: Institut Français du Proche-Orient.

BOYLAN, P.J. 2002. The concept of cultural protection in times of armed conflict: from the crusades to the new millennium, in N. Brodie \& K. Walker Tubb (ed.) Illicit antiquities: the theft of culture and the extinction of archaeology: 43-108. London: Routledge.
BuRCKHARDT, J.L. 1822. Travels in Syria and the Holy Land. London: John Murray.

CunlifFe, E. 2012. Damage to the soul: Syria's cultural heritage in conflict. Durham: Durham University \& Palo Alto (CA): Global Heritage Fund. Available at: http://ghn.globalheritagefund.com/uploads/ documents/document_2107.pdf (accessed 23 December 2014).

FISK, R. 1993. The biggest supermarket in Lebanon: a journalist investigates the plundering of Lebanon's cultural heritage. Berytus 39: 243-52.

Hamilakis, Y. 2009. The "War on Terror" and the military-archaeology complex: Iraq, ethics, and neo-colonialism. Archaeologies: Journal of the World Archaeological Congress 5(1): 39-65. http://dx.doi.org/10.1007/s1 1759-009-9095-y

C Antiquity Publications Ltd, 2015 
Heinz, M. with S. Kulemann-Ossen, J. Linke \& E. WaGner. 2010. Kamid el-Loz. Intermediary between cultures: more than 10 years of archaeological research in Kamid el-Loz (1997 to 2007). (BAAL Hors-Série VII). Beirut: Ministry of Culture, Directorate General of Antiquities.

HIRST, D. 2010. Beware of small states: Lebanon, battleground of the Middle East. London: Faber and Faber.

ICRC International Committee of the Red Cross. n.d. Treaties and documents by state: Lebanon. Available at: http://www.icrc.org/applic/ihl/ihl.nsf/ vwTreatiesByCountrySelected.xsp?xp_ countrySelected=LB (accessed 23 December 2014)

KRENCKer, D. \& W. ZsChieTZSChMANN. 1938. Römische Tempel in Syrien, nach Aufnahmen und Untersuchungen von Mitgliedern der deutschen Baalbekexpedition 1901-1904. Berlin: de Gruyter.

Marfoe, L. 1978. Between Qadesh and Kumidi: a history of the frontier settlement and land use in the Biqa', Lebanon. Unpublished PhD dissertation, University of Chicago.

- 1995. Kämid el-Loz 13. The prehistoric and early historic context of the site: catalog and commentary. Bonn: Habelt.

- 1998. Kamid el-Loz 14. Settlement history of the Biqā up to the Iron Age. Bonn: Habelt.

MilsteIn, M. 2006. Lebanon historic sites again escape conflict unscathed. Available at: http://news. nationalgeographic.com/news/2006/08/ 060828-lebanon-ruins.html (accessed 23 December 2014).

Newson, P. \& R. Young. 2014. Archaeological assessment of the site at Hosn Niha: preliminary report 2011-2012. BAAL: Bulletin d'Archéologie et d'Architecture Libanaises 15: 21-46.

Nordiguian, L. 2005. Temples de l'époque romaine $d u$ Liban. Beirut: Presses de l'Université Saint-Joseph.

SAVAGE, S.H. \& S.G. RemPEL. n.d. Climate change and human impact on ancient and modern settlements: identification and condition assessment of archaeological sites in the northern Levant from Landsat, ASTER and CORONA imagery. Available at: http://gaialab.asu.edu/home/NasaReport. php\#Ghassil (accessed 23 December 2014).
SeEden, H. 1989. Bulldozers destroyed what scientific archaeology exposed. Berytus 37: 3-4.

STONE, P.G. 2013. A four-tier approach to the protection of cultural property in the event of armed conflict. Antiquity 87: 166-77.

StOne, P.G. \& J. FARAKH BAJJALy. 2008. Introduction, in P.G. Stone \& J. Farakh Bajjaly (ed.) The destruction of cultural heritage in Iraq: 1-17. Woodbridge: Boydell.

TAHAN, L.G. 2006. Lebanon: cultural heritage threatened by the war in Lebanon in 2006. ICOMOS. Available at: http://www.icomos. org/en/get-involved/inform-us/heritage-alert/ heritage-at-risk-reports/116-english-categories/ resources/publications/207-icomos-world-report2006-2007-on-monuments-and-sites-in-danger (accessed 23 December 2014).

ThORPE, I.J.N. 2003. Anthropology, archaeology, and the origin of warfare. World Archaeology 35: 145-65. http://dx.doi.org/10.1080/ 0043824032000079198

UNESCO. n.d. Lebanon. Available at: http://whc.unesco.org/en/statesparties/LB/ (accessed 23 December 2014).

WARD, W.A. 1994. Archaeology in Lebanon in the twentieth century. The Biblical Archaeologist 57: 66-85. http://dx.doi.org/10.2307/3210385

Warren, C. 1870. The temples of Coele-Syria. Palestine Exploration Fund Quarterly Statement: 183-210.

YASMine, J. 2005. Remaniements de temples d'époque romaine: les cas de Niha et de Faqra. L'apport de l'étude métrologique. BAAL: Bulletin d'Archéologie et d'Architecture Libanaises 9: 301-16.

- 2006. Complexes cultuels ruraux d'époque romaine dans la Beqaa (Liban): le cas de Hosn-Niha: problèmes d'architecture et d'archéologie. Unpublished PhD dissertation, University of Paris I Sorbonne.

- 2009. Transformations monumentales de sanctuaires et de temples ruraux antiques: les cas de Hardine et de Niha. Topoi 16: 121-52. 